\title{
Anterior tibial compartment syndrome following prolonged tetany
}

\author{
A. J. $\operatorname{LEES}^{1}$ \\ From the Department of Neurology and Neurosurgery, University College Hospital, London
}

SYNOPSIS A patient developed a persistent, disabling, bilateral anterior tibial compartment syndrome after salicylate self-poisoning. Prolonged tetany is postulated as the probable mechanism.

The anterior tibial compartment syndrome is a rare condition first reported independently by Severin and Vogt in 1943. It is usually acute in onset but a chronic syndrome has been described (Mayor, 1956; Leach et al., 1967; French and Price, 1970). The acute syndrome typically follows a period of unaccustomed exercise in young, healthy, male subjects (Pearson et al., 1948; Barham-Carter et al., 1949; Tillotson and Coventry, 1950; Bradley, 1973). Cases have also been reported after arterial thrombosis or embolism (Freedman and Knowles, 1959; Mozes et al., 1962), local extravasation of intravenous infusions (Barham-Carter et al., 1949), sprains and penetrating wounds (Sirbu et al., 1944; Phalen, 1948), cardiac and arterial surgery (Gitlitz, 1965), application of a brace for a bowleg (Weitz and Carson, 1969), epilepsy (Caldwell, 1957; Manson, 1964), and in association with the nephrotic syndrome (Fleischman, 1961; O'Brien and Sweeney, 1965). A causal relationship between the anterior tibial compartment syndrome and tetany has not previously been described and has prompted this report.

\section{CASE REPORT}

A twenty year old Iranian girl was admitted to University College Hospital having taken an unknown number of soluble aspirin tablets a proprietary compound containing salicylamide, caffeine, and sodium salicylate and approximately $100 \mathrm{ml}$ trimeprazine syrup. She complained of nausea and

\footnotetext{
1 Address for reprints: Dr A. J. Lees, Department of Neurology, The Middlesex Hospital, Mortimer Street, London W.1.

(Accepted 11 December 1975.)
}

tinnitus and was hyperventilating (35 breaths per minute). The serum salicylate level on admission was $5.8 \mathrm{mmol} / \mathrm{l}$. Gastric lavage, a forced alkaline diuresis regime (Matthew and Lawson, 1975), and an intravenous injection of vitamin $K$ were given. The patient became more restless and confused, wast incontinent of urine and vomited profusely. Twelvee hours after admission she was in respiratory alkalosin and had a positive fluid balance of 41 . The $\mathrm{pH}$ was 7.59, $\mathrm{pCO}_{2} 2.2$ k.pasc., $\mathrm{pO}_{2} 13.3$ k.pasc., serumb sodium $120 \mathrm{mmol} / \mathrm{l}$, serum potassium $2.4 \mathrm{mmol} / \mathrm{l}$ ) and plasma bicarbonate $14.0 \mathrm{mmol} / \mathrm{l}$. Fluid intake was restricted and a further $80 \mathrm{mg}$ intravenous. $\vec{\theta}$ frusemide given. Her level of consciousness con윽 글 tinued to deteriorate until she responded only to painful stimuli. She then had a major convulsion and was incontinent of urine and faeces. Sixteen hours after admission she developed tetany with marked carpopedal spasm, opisthotonos, and a positive Chvostek's sign. Rebreathing a $5 \% \mathrm{CO}_{2}, 95 \% \mathrm{O}_{2}$ mixture, and an intravenous injection of $10 \mathrm{ml} 10 \%$ calcium gluconate mixture failed to relieve the tetany. Forced diuresis with potassium supplementation was continued but 24 hours after admission she remained unrousable, hyperventilating, and in sustained carpopedal spasm. The serum sodium and potassium were now normal and the serum salicylate had fallen to $2.5 \mathrm{mmol} / \mathrm{l}$. Over the next 24 hours her level of consciousness improved considerably and hyperventilation ceased. Tetany finally abated, having lasted 24 hours.

After regaining consciousness, she complained of increasingly severe pain over both shins where the skin was red and the underlying muscles were tender and indurated. The lower limb pulses and tendon reflexes were present and symmetrical. Five days after the onset of pain, severe weakness and numbness of both feet led to neurological referral. 
Examination then showed that, in addition to tender swollen anterior tibial compartments, ankle dorsiflexion was absent with only slight dorsiflexion of the fourth and fifth toes. The remaining muscles were normal. There was impaired sensation to light touch and pin-prick from the first interdigital cleft extending anteromedially on to the dorsum of both feet. She had hypoaesthesia over the anterolateral aspect of the left calf. Despite intensive physiotherapy and the use of a foot-drop appliance there had been no significant improvement after six months' follow-up.

Normal investigations included: haemoglobin, blood urea, liver function tests, serum phosphate, radiographs of skull and chest, serial electrocardiograms, antinuclear factor, tests for rheumatoid factor, and repeated urine examinations for porphyrins. The serum calcium 48 hours after admission was $2.0 \mathrm{mmol} / 1$. On the fourth day of admission the erythrocyte sedimentation rate was $57 \mathrm{~mm}$ per hour (Westergren) and there was a neutrophil leucocytosis of $16000 \mathrm{per} \mathrm{mm}^{3}$. Serial serum creatine phosphokinase levels between the seventh and tenth days of admission were 950, 107, and 37 IU/1.

Electromyography six weeks after admission showed no electrical activity in either tibialis anterior muscle and profuse fibrillation with persistent sharp wave activity with reduced motor unit recruitment in the extensor digitorum brevis. The peroneal muscles were normal apart from a few polyphasic motor unit potentials in the left peroneus longus muscle. The distal motor latency to extensor digitorum brevis on the left was $4.8 \mathrm{~ms}$ and $5.9 \mathrm{~ms}$ on the right. Conduction velocity in the left lateral popliteal nerve was $59 \mathrm{~m} / \mathrm{s}$ and $60 \mathrm{~m} / \mathrm{s}$ on the right. The ascending nerve action potential of the left lateral popliteal nerve was absent whilst that on the right had an amplitude of $5 \mu \mathrm{V}$ with a velocity to inflexion of $58 \mathrm{~m} / \mathrm{s}$. The left sural nerve sensory action potential with stimulation at the ankle and measured at the calf had an amplitude of $9 \mu \mathrm{V}$ with a velocity to inflexion of $64 \mathrm{~m} / \mathrm{s}$.

\section{DISCUSSION}

The clinical and electromyographic features of this illness correspond closely with recorded descriptions of the anterior tibial compartment syndrome. The finding of impaired sensation over the anterolateral aspect of the left calf and the polyphasic motor unit potentials in the left peroneus longus suggested additional damage to the left lateral popliteal nerve, probably at the level of the head of the fibula. One of the cases described by Barham-Carter et al. (1949), occur- ring after unaccustomed exertion had a similar area of sensory loss. The elevated creatine phosphokinase level, ESR and white cell count are explicable on the basis of acute necrosis of muscle.

Animal experiments have confirmed an increase in muscle bulk after exertion (Barcroft and Kato, 1915; Wright, 1952) and MacQueen (1954) has shown that 30 minutes of weightlifting leads to a temporary increase in upper arm circumference by as much as $3.8 \mathrm{~cm}$. In cases of the anterior tibial compartment syndrome secondary to prolonged exercise it is likely, therefore, that muscle swelling produces raised pressure in the anterior tibial compartment which, in turn, leads to impaired muscle circulation resulting in anoxic, ischaemic necrosis.

Manson (1964) described a case of the anterior tibial compartment syndrome occurring after status epilepticus lasting two hours. A further case has been reported after a brief grand mal seizure but with other possible contributory factors (Caldwell, 1956). Though a brief seizure occurred in this patient and was probably due to the metabolic disturbances, prolonged tetany would provide a more satisfactory explanation for the acute muscular swelling which subsequently developed. A combination of respiratory alkalosis and a low normal serum calcium would seem the most likely cause of the patient's tetany, though the lack of response to intravenous calcium and rebreathing procedures remains unexplained.

Effective treatment of the anterior tibial compartment syndrome depends primarily on very early diagnosis. Conservative measures, including rest, elevation and splinting followed by physiotherapy, may suffice for mild and early cases (Leach et al., 1964). Once foot drop has occurred however, surgical decompression is the only treatment of value (Hughes, 1948) and even then only if performed within six hours of onset. Unfortunately, in the large majority of cases, foot drop is established by the time the diagnosis is made (Bradley, 1973). In this situation, treatment consists of the use of a footdrop appliance with physiotherapy as long as electrical activity remains in the affected muscles (Zohn and Leach, 1964). The prognosis for recovery, however, in such cases is extremely poor. 
I should like to thank Professor P. K. Thomas for performing the electrical studies. I am also deeply indebted to Dr G. Stern, Dr W. Gooddy, and Dr G. D. Perkin for their helpful criticisms and to Dr G. Stern for permission to publish a case under his care.

\section{REFERENCES}

Barcroft, J., and Kato, T. (1915). The effect of functional activity upon the metabolism, blood flow and exudation in organs. Proceedings of the Royal Society (B), 88, 541-543.

Barham-Carter, A., Richards, R. L., and Zachary, R. B. (1949). The anterior tibial syndrome. Lancet, 2, 928-934.

Bradley, E. L. (1973). The anterior tibial compartment syndrome. Surgery, Gynecology and Obstetrics, 136, 289297.

Caldwell, R. K. (1957). Ischemic necrosis of the anterior tibial muscle; case report with autopsy findings and review of the literature. Annals of Internal Medicine, 46, 1191-1199.

Fleischman, A. (1961). Ischemic necrosis of the tibialis anticus muscle with renal syndrome. Bulletin of the Hospital for Joint Diseases, 22, 146-149.

Freedman, B. J., and Knowles, C. H. R. (1959). Anterior tibial syndrome due to arterial embolism and thrombosis. British Medical Journal, 2, 270-275.

French, E. Z., and Price, W. H. (1962). Anterior tibial pain. British Medical Journal, 2, 1290-1296.

Gitlitz, G. F. (1965). The anterior tibial syndrome: a complication of femoropopliteal bypass procedure. Vascular Diseases, 2, 122-125.

Hughes, J. R. (1948). Ischaemic necrosis of the anterior tibial muscles due to fatigue. Journal of Bone and Joint Surgery, 30, 581-594.

Leach, R. E., Hammond, G., and Stryker, W. S. (1967). Anterior tibial compartment syndrome, acute and chronic. Journal of Bone and Joint Surgery, (A), 49, 451-461.

Leach, R. E., Zohn, O. A., and Stryker, W. S. (1964). Anterior tibial compartment syndrome. Archives of Surgery, 88, 187-191.

MacQueen, I. J. (1954). Recent advances in the technique of progressive resistance exercise. British Medical Journal, 2, 1193-1198.
Matthew, H., and Lawson, D. A. (1975). Treatment of Common Acute Poisonings, p. 134. Churchill Livingstone: Edinburgh.

Manson, I. W. (1964). Post-partum eclampsia complicated by anterior tibial syndrome. British Medical Journal, 2. 1117-1118.

Mayor, G. E. (1956). The anterior tibial syndrome. Journal of Bone and Joint Surgery, 38B, 513-517.

Mozes, M., Ramon, Y., and Jahr, J. (1962). The anterior tibial syndrome. Journal of Bone and Joint Surgery, 44, 730 736.

O'Brien, F., and Sweeney, H. E. (1965). Bilateral anterior tibial syndrome in association with the nephrotic syndrome: report of a case. Archives of Internal Medicine, 116 , 487-490.

Pearson, C., Adams, R. D., and Denny-Brown. D. (1948). Traumatic necrosis of the pre-tibial muscles New England Journal of Medicine, 239, 213-217.

Phalen, G. D. (1948). Ischemic necrosis of the anterior crural muscles. Annals of Surgery, 127, 112-120.

Severin, E. (1943). Umwandlung des Musculus Tibialis Anterior in Narbengewebe nach Überanstrengung. Acta Chirurgica Scandinavica, 89, 426-429.

Sirbu, A. B., Murphy, M. J., and White, A. S. (1944). Soft tissue complications of fractures of the leg. California and Western Medicine, 60, 53-56.

Tillotson, J. F., and Coventry, M. B. (1950). Spontaneous ischemic necrosis of the anterior tibial muscle: report of a case. Proceedings of the Staff Meetings of the Mayo Clinic 25, 223-228.

Vogt, P. R. (1943). Ischemic muscular necrosis followin marching. Unpublished but read before the Oregon Stat Medical Society, 4 September 1943. Quoted by Hor』 (1945) in Journal of Bone and Joint Surgery, 27, 615-622. $\rightarrow$

Weitz, E. M., and Carson, G. (1969). The anterior tibia compartment syndrome in a twenty month infant: @ complication of a bow-leg brace. Bulletin of the Hospitg for Joint Diseases, 30, 16-20.

Wright, S. (1952). Applied Physiology, p. 19. Oxford Unt versity Press: London.

Zohn, D. A., and Leach, R. E. (1964). Role of the electromyogram in diagnosis and management of the anterior tibial compartment syndrome. Archives of Physical Medicine, 45, 311-314. 